\title{
Selbstbestimmung ist nicht genug
}

\section{Rouven Porz}

PD Dr. phil., dipl. biol., Direktion Medizin, Medizinethik Insel Gruppe AG (Bern), Gastwissenschaftler der VU Amsterdam,

Präsident der European Association of Centres of Medical Ethics (EACME) und Mitglied der Redaktion Ethik der SÄZ

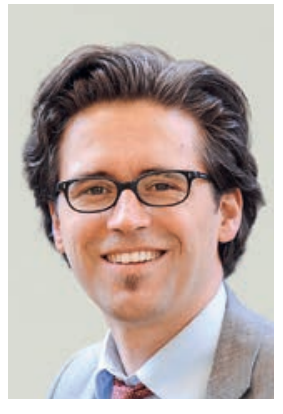

Ich finde, wir übertreiben es manchmal mit der Idee der Selbstbestimmung. Insbesondere im Gesundheitswesen. Und ganz besonders in den ethischen Überlegungen zu unserem Gesundheitswesen. Es gibt so viele schöne Werte in der Ethik und Philosophie, Vertrauen, Mut, Verantwortung, Besonnenheit, Solidarität, Loyalität, Gerechtigkeit, Beziehungen; aber nein, irgendwie bleiben wir immer bei dieser Selbstbestimmung (bzw. Autonomie) hängen.

Jetzt verstehen Sie mich nicht falsch. Ich weiss, es braucht Selbstbestimmung. Selbstbestimmung ist die wichtigste individuelle Basis, auf der unsere Demokratie aufgebaut ist. Vollkommen klar. Jeden Tag erreichen uns erschreckende Bilder und Beispiele in den Nachrichten von Ländern dieser Welt, in denen keine Demokratie herrscht oder in denen die Demokratie untergraben wird. Das ist schlimm. Ich rede nicht davon, dass Selbstbestimmung eine schlechte Sache ist, wirklich gar nicht, im Gegenteil, wir brauchen politische Selbstbestimmung. Ich sage nur, dass wir es in unserem Gesundheitswesen mit der Selbstbestimmung etwas übertreiben. Oder sagen wir so: Wir machen es uns (als Gesundheitsfachpersonen) mit der Selbstbestimmung unserer Patientinnen und Patienten oft etwas zu einfach.

Viel besser - als ich es hier kann - wird meine Skepsis gegenüber der Dominanz der Selbstbestimmung von dem deutschen Medizinethiker, Philosophen und Arzt Giovanni Maio ausgedrückt. Man könnte es kaum besser auf den Punkt bringen. Er schreibt in Bezug auf unsere medizinethischen Überlegungen in unseren westlichen Gesundheitssystemen: "Eine Gesellschaft, die inhaltliche Vorgaben für die Bewertung des guten Lebens oder des guten Sterbens nicht akzeptieren möchte, scheint sich nur noch darauf verständigen zu können, dass es dem Einzelnen überlassen bleiben muss, solche Werte zu setzen. Daher macht unsere Gesellschaft das Prinzip der Autonomie zum Garanten einer für alle akzeptablen Ethik. Hier muss natürlich auch bedacht werden, dass eine solche Ethik in gewisser Weise eine inhaltliche Resignation darstellt (...).» ${ }^{1}$ Genau, eine Resignation! Wenn wir uns immer nur auf die Selbstbestimmung beziehen, dann handelt es sich hierbei eigentlich um eine blutleere und farblose Ethik, weil wir uns gar nicht mehr trauen, gemeinsam darüber nachzudenken, welche Werte wir gemeinsam leben wollen oder nicht. Die Wertefrage wird reine Privatsache. Das scheint politisch korrekt, meine Werte sind meine Sache, aber es führt auch leicht in eine individuelle Einsamkeit und Isolation. Was ich sagen will, ist: Nehmt eure Werte raus und legt sie diskursiv auf den Tisch. Die alleinige Verwendung des Prinzips der Autonomie ist kein Garant für eine gute Ethik. Es ist eher ein Zeichen einer inhaltlich-intellektuellen Verarmung.

Natürlich, mag der eine oder andere jetzt skeptisch denken, schön und gut, aber das klappt ja nicht, dass wir andere Werte benutzen. Schliesslich fusst ja auch unser Rechtssystem auf der Selbstbestimmung des Einzelnen. Nehmen wir doch nur mal die «Urteilsfähigkeit> von Patienten. Gerade die Feststellung von Urteilsfähigkeit müsste doch bedeuten, dass Selbstbestimmung immer der wichtigste Wert ist, oder? Nein, ich muss sagen, das würde ich nuancierter sehen. Die Feststellung von Urteilsfähigkeit (z.B. bei älteren Patienten oder bei Unfallopfern) erlaubt uns, einen ersten wichtigen Scheideweg in der Behandlung dieser Patienten festzustellen: Kann der Patient in Bezug auf die anstehende Entscheidung selbstbestimmt mitdenken oder nicht (urteilsfähig, ja oder nein). Das heisst aber gar nicht, dass Selbstbestimmung der wichtigste Wert genau dieses Patienten sein muss. Angenommen er kann selbständig mitdenken (urteilsfähig) und sagt zu uns: «Das verstehe ich alles, aber ich brauche noch etwas Zeit. Das möchte ich nicht selbständig entscheiden. Können Sie mir einen alternativen medizinischen Vorschlag machen, den ich auch mit meiner Frau und meinen Kindern in Ruhe besprechen kann?» Hier hat jemand den Mut, Ihnen als Arzt zu widersprechen. Hier fordert jemand Ihr Fachwissen ein, hier hat jemand offensichtlich auch Vertrauen in Ihr Fachwissen. Hier möchte sich jemand zudem in Beziehung setzen zu seinen Familienangehörigen. Solche Situationen sind von solch einem reichhaltigen Wertekanon untermauert; die Reduktion auf die vermeintliche Selbstbestimmung ist ganz einfach nicht genug. 